\title{
Who Should Act as Lender of Last Resort? An Incomplete Contracts Model
}

\author{
Rafael Repullo \\ CEMFI and CEPR
}

Working Paper No. 9913

October 1999

This is a completely revised version of an earlier paper entitled "Who Should Decide on Bank Closures? An Incomplete Contracts Model". I want to thank Philippe Aghion, Patrick Bolton, Martin Hellwig, Richard Kihlstrom, Colin Mayer, Jorge Padilla, JeanCharles Rochet, Javier Suarez, and especially Miguel Pellicer for helpful discussions. I gratefully acknowledge research funding from the Spanish DGES, Grant PB97-0155.

(E-mail address: repullo@cemfi.es).

CEMFI, Casado del Alisal 5, 28014 Madrid, Spain.

Tel: 3491 4290551, fax: 3491 4291056, www.cemfi.es. 


\begin{abstract}
This paper presents a model of a bank subject to liquidity shocks that require borrowing from a lender of last resort. Two government agencies with different objectives may perform this function: a central bank and a deposit insurance corporation. Both agencies supervise the bank, i.e. collect nonverifiable information about its financial condition, and use this information to decide whether to support it. It is shown that the optimal institutional design involves the two agencies: the central bank being responsible for dealing with small liquidity shocks, and the deposit insurance corporation for large shocks. Furthermore, except for very small shocks, they should lend at penalty rates.
\end{abstract}

Keywords: lender of last resort, bank supervision, central banking, deposit insurance, incomplete contracts.

JEL Classification: E58, G21, G28. 


\section{Introduction}

Commercial banks are institutions that typically have a large proportion of their assets in the form of illiquid bank loans and a large proportion of their liabilities in the form of deposits callable on demand. ${ }^{1}$ With this balance sheet structure, a sufficiently large deposit withdrawal may put the bank in a very difficult position. The same informational reasons that make bank loans illiquid imply that the bank may not be able to borrow the required funds from other banks, ${ }^{2}$ in which case the liquidity problem may lead to insolvency, and eventually force the bank into liquidation.

From their inception, central banks have undertaken as one of their key responsibilities to provide liquidity to banks unable to find it elsewhere. The traditional doctrine on this lender of last resort (LLR) activity was put forward by Walter Bagehot (1873, pp. 96-97): "Nothing, therefore, can be more certain than the Bank of England... in time of panic must advance freely and vigorously... The end is to stay the panic... And for this purpose there are two rules: First. That these loans should only be made at very high rate of interest... Secondly. That at this rate these advances should be made on all good banking securities, and as largely as the public ask for them."

There may be, however, a contradiction between the aim of "staying the panic" and the requirement to lend on "good banking securities". If a security is known to be good, then presumably the bank would be able to sell it to other banks or to borrow from them posting the security as collateral, in which case the LLR would not be needed. So it must be the case that the securities that the bank in trouble is able to offer are not publicly known to be good, which implies that either the central bank has more information than private banks or it is willing to lend on the basis of collateral of uncertain value (or both).

The obvious source of an informational advantage for the central bank vis-à-vis private banks is bank supervision. Since bank examiners have access to the bank's confidential loan files, they can acquire private information on the financial condition

\footnotetext{
${ }^{1}$ The literature on financial intermediation that started with Diamond (1984) has provided a rationale for this structure in terms of information and monitoring costs.

${ }^{2}$ Morgan (1998) shows that credit rating agencies disagree more over bond issues by banks than over issues by non-bank firms. Moreover, the proportion and size of disagreements increases as banks substitute loans for securities, suggesting that it is lending that makes banks opaque.
} 
of the bank, and hence make it possible to implement LLR decisions conditional on this information.

The fact that not all requests for LLR lending will be accepted implies that depositors face some risk that their bank will be allowed to fail, and so the incentive to run on the basis of whatever is perceived as bad news will not disappear. Although monitoring by depositors and the threat of an information-based run may have good incentive effects on risk-taking (as stressed by Calomiris and Kahn, 1991), it has been argued (by Dewatripont and Tirole, 1994, among others) that depositors do not typically have the ability or the incentive to monitor the bank.

At any rate, the objective of protecting small uninformed investors has led to the widespread establishment of deposit insurance systems. Funded by premia from the insured banks, and in many cases with implicit or explicit government backing, these institutions have become responsible for dealing with solvency problems, leaving central banks with the exclusive role of handling liquidity problems. This allocation of responsibilities raises, however, the difficult practical issue of distinguishing between liquidity and solvency problems. More fundamentally, there is the theoretical issue of whether this allocation can be given some rationale.

The purpose of this paper is to construct a model to address the optimal allocation of LLR responsibilities between the central bank and the deposit insurance corporation. Given the connection between LLR lending and bank supervision noted above, the model can also shed some light on the issue of which of these two government agencies should be in charge of bank supervision.

The model considers a bank that raises deposits that are fully insured by a deposit insurance corporation, and invests them in illiquid assets. The bank is subject to liquidity shocks (deposit withdrawals). Since the bank's assets are completely illiquid, ${ }^{3}$ faced with a shock the bank can either succeed in borrowing the required funds from a LLR or fail, in which case it is liquidated. ${ }^{4}$ To perform the liquidity provision function, the LLR supervises the bank, i.e. collects information about the value of its assets. This information is assumed to contain qualitative assessments (of the internal organization of the bank, the quality of its management, etc.) that make

\footnotetext{
${ }^{3}$ In Section 4.1 we allow for the possibility of investment in liquid assets.

${ }^{4}$ Notice that the bank is not closed by the LLR (in the sense of withdrawal of license), but it is liquidated by private creditors; see Mailath and Mester (1994) for a model of bank closures.
} 
it nonverifiable.

Two agencies can perform the role of LLR. The first is the deposit insurance corporation. This means that the corporation has either sufficient liquid funds or is able to borrow without limit from a second agency called the central bank. This agency is the ultimate source of liquidity, and consequently can also act as LLR. ${ }^{5}$ Both agencies have the same ability with regard to bank supervision, and in fact we assume that they collect the same information. ${ }^{6}$

If the two agencies were social welfare maximizers there would be no problem: either of them would implement the optimal LLR decision given the supervisory information about the state of the bank. However, we are going to take a political economy perspective according to which government agencies have their own objective functions that need not correspond with the maximization of social welfare. In particular, we assume that the deposit insurance corporation cares about its exposure to the risk of having to compensate depositors following a bank failure, while the central bank does not have such liability, and cares about the implications of a bank failure for the stability of the banking system. Moreover, both agencies take into account the expected return from their LLR lending. ${ }^{7}$

The fact that the objective function of these agencies does not correspond with the maximization of social welfare would not pose a problem if the supervisory information were verifiable: any of the two agencies could be instructed to implement the optimal LLR decision. However when this information is not verifiable, the agencies are able to pursue their own distinct objectives, and so their LLR decisions will in general be different (and suboptimal).

Given this setup, we will follow the literature on incomplete contracts (in particular, Aghion and Bolton, 1992, and Dewatripont and Tirole, 1993) that allows the allocation of control to be contingent on any information that is verifiable. In particular, we will assume that the size of the bank's liquidity shock is verifiable, so the

\footnotetext{
${ }^{5}$ Of course, the central bank has additional macro-monetary functions that are outside the scope of the model.

${ }^{6}$ Although it could be argued that the central bank may have an advantage because of the information acquired in monitoring the payment system, we do not want to focus the discussion on differences in information.

${ }^{7}$ This means that even if the central bank (the deposit insurance corporation) fully transfer its profits (losses) to the Treasury, for either pecuniary or nonpecuniary reasons they still care about the net result of their operations.
} 
allocation of LLR responsibilities may be contingent on the size of the shock. Since the agencies do not maximize social welfare, welfare losses will occur. The optimal allocation of responsibilities then follows from the comparison, for each possible value of the liquidity shock, of the losses associated with allocating control to the central bank and allocating control to the deposit insurance corporation.

The main result of the paper is that for small liquidity shocks (relative to the size of the bank's balance sheet) the central bank should be the LLR, while for large shocks the LLR decision should correspond to the deposit insurance corporation. Moreover, the central bank should charge the (risk unadjusted) market interest rate for very small loans, gradually increasing the rate as the size of the loan increases, while the deposit insurance corporation should always charge penalty rates.

Assuming than small shocks are more common than large ones, the optimal allocation of LLR responsibilities suggests that, in order to avoid duplication of supervisory costs, the central bank should be in charge of bank supervision. Then in the case of large shocks, the central bank would hand over all the relevant information to the deposit insurance corporation.

The model in this paper can also be used to provide a rationale for a standard feature of central bank LLR policy, namely the principle of "constructive ambiguity." This is taken to mean that central banks do not typically spell out beforehand the procedural and practical details of their LLR policy. ${ }^{8}$ One possible rationalization of this principle is based on the idea of the central bank committing to a mixed strategy, which reduces ex ante risk-shifting incentives at the cost of ex post inefficient liquidations; see Freixas (1999). Our model supports a different story, which has been suggested by Goodfriend and Lacker (1999), in which the policy is not random from the perspective of the central bank, but it is perceived as such by outsiders that cannot observe the supervisory information on the basis of which each decision is made. In other words, the randomness lies in the supervisory information, not in the policy rule.

The theoretical literature on the LLR is not very large. Apart from Freixas (1999),

\footnotetext{
${ }^{8}$ To testify that this is not a recent phenomenon one can cite again Bagehot (1873, p. 101): "In common opinion there is always great uncertainty as to the conduct of the Bank... The public is never sure what policy will be adopted... what amount of advance will be made, or on what security it will be made."
} 
one can cite Bhattacharya and Gale (1987), who characterize the role of the central bank as a mechanism for risk-sharing across banks that are subject to privately observed liquidity shocks, Flannery (1996), who provides a rationale for the LLR during financial crises, Rochet and Tirole (1996), who discuss central bank lending in a model with interbank monitoring and lending, and Freixas, Parigi and Rochet (1999), who analyze interbank networks focusing on the role of the central bank in avoiding possible liquidity shortages. Finally, from a somewhat different perspective, Goodhart and Huang (1999) present a model in which bank failures introduce macroeconomic uncertainty that justifies central bank lending to big banks, i.e. a "too big to fail" policy.

The paper is organized as follows. Section 2 presents the model and discusses the first-best LLR policy as well as the policies implemented by the central bank and the deposit insurance corporation. Section 3 then characterizes the optimal allocation of LLR responsibilities. Section 4 considers three extensions: allowing for the possibility of investing in liquid assets, introducing bank capital, and allowing for penalty rates. Section 5 shows how the results can be extended to a more general setup. Finally, Section 6 offers a few concluding remarks.

\section{The Model}

Consider a model of a risk-neutral bank that at an initial date $t=0$ raises an amount of deposits which is normalized to 1 . These funds are invested in an illiquid asset that yields a random return $\widetilde{R}$, with $E(\widetilde{R})>1$, at a final date $t=2 .{ }^{9}$ Because of asymmetric information, there does not exist a market for this asset at an intermediate date $t=1$. However, the bank can be liquidated at this date, in which case the liquidation value of the asset is $L \in(0,1)$. Deposits are assumed to be fully insured by a deposit insurance corporation, and can be withdrawn at either $t=1$ or $t=2$. To simplify the presentation, interest rates and flat deposit insurance premia will be normalized to zero.

At $t=1$ a fraction $v \in[0,1]$ of the deposits are withdrawn. Since there is no market for the asset, if $v>0$ the bank will be forced into liquidation unless it

\footnotetext{
${ }^{9}$ Notice that we initially assume that the bank has no capital. This assumption will be relaxed in Section 4.2 .
} 
can borrow from some lender of last resort (LLR) the funds required to pay back depositors. ${ }^{10}$ If the bank is liquidated, there is a bankruptcy cost $c$ which comprises the administrative costs of closing the bank and paying back depositors (incurred by the deposit insurance corporation) and the negative externalities associated with a bank failure (contagion to other banks, breakup of lending relationships, etc.). We assume that the bankruptcy cost $c$ is smaller than $1-L$.

Two different government agencies can be chosen to act as LLR: the central bank and the deposit insurance corporation. To perform this function, the chosen agency is given authority to supervise the bank in order to gather information about the future return of the bank's asset. Bank supervision leads to the observation of a signal $u \in[0,1]$ at $t=1$ that contains information about $\widetilde{R}$. In particular, it is assumed that

$$
\widetilde{R}=\left\{\begin{array}{l}
0, \quad \text { with probability } 1-u \\
R, \quad \text { with probability } u
\end{array},\right.
$$

where $R>1$.

From the point of view of the initial date $t=0$, both supervisory information and deposit withdrawals are independent random variables, denoted $\widetilde{u}$ and $\widetilde{v}$, with cumulative distribution functions $F(u)$ and $G(v)$, respectively. ${ }^{11}$

There is, however, an important contractual difference between $u$ and $v$. Deposit withdrawals $v$ are assumed to be publicly observable and verifiable at $t=1$. On the other hand, the signal $u$ observed by bank examiners is nonverifiable. This implies that the decision to support the bank or not cannot be specified ex ante as a function of the realization of $\widetilde{u}$, but will depend on the evaluation of the case by the agency responsible for LLR operations.

Each agency is assumed to care about the expected value of its final wealth net of the costs incurred in dealing with a bank failure. Given this objective function, the two agencies may have different views on whether to support a bank with liquidity problems. There are two reasons for this. First, the deposit insurance corporation is obliged to compensate depositors if the bank fails, whereas the central bank does not have such liability. Second, we assume that the central bank incurs a fraction

\footnotetext{
${ }^{10}$ Clearly, we are implicitly assuming some capital market imperfection that makes it impossible for the bank owners to raise equity overnight.

${ }^{11}$ Notice that $E(\widetilde{R})=E(E(\widetilde{R} \mid u))=R E(\widetilde{u})>1$ requires $E(\widetilde{u})>1 / R$.
} 
$\beta \in(0,1)$ of the bankruptcy cost $c$, while the deposit insurance corporation incurs a fraction $\gamma \in(0,1)$ of the cost $c .^{12}$

In what follows we will characterize the LLR policy of the central bank and the deposit insurance corporation. But first it is convenient to discuss the benchmark case in which the signal $u$ is verifiable.

Optimal LLR policy To derive the LLR policy under verifiable information we compare the expected return of the bank's asset net of expected future bankruptcy costs, $u R-(1-u) c$, with the liquidation value of the bank's asset net of bankruptcy costs, $L-c$. Hence the optimal LLR policy is to support the bank if

$$
u R-(1-u) c \geq L-c
$$

that is if

$$
u \geq u^{*} \equiv \frac{L}{R+c}
$$

Since $0<L<1<R$ and $c>0$ we have $u^{*} \in(0,1)$.

It should be noted that deposit withdrawals $v$ are irrelevant for the optimal LLR policy, since they do not contain any information on $\widetilde{R} .^{13}$

Central bank LLR policy Suppose that the central bank is the LLR, and consider a situation in which after observing the signal $u$ the central bank has to decide whether to lend the bank the amount $v$ or let it fail. We initially assume that in the former case the central bank only charges the (risk unadjusted) market interest rate, which is normalized to zero. ${ }^{14}$ Hence when $\widetilde{R}=R$ the bank will pay back the remaining depositors the amount $1-v$ and the central bank the amount $v$, whereas when $\widetilde{R}=0$ limited liability implies that neither depositors nor the central bank will get

\footnotetext{
${ }^{12}$ In general we would expect $\beta+\gamma<1$, since the agencies may not fully take into account the externalities associated with a bank failure. On the other hand, career concerns of the top officials of these agencies may work in the opposite direction.

${ }^{13}$ This assumption can be justified by the fact that depositors are fully insured, so they have no incentive to gather information and decide whether to withdraw on the basis of this information. On the other hand, one would get the same result in a model where $v$ contained information on $\widetilde{R}$, as long as $u$ incorporated this information (in which case $\widetilde{u}$ and $\widetilde{v}$ would be correlated).

${ }^{14}$ In Section 4.3 we will allow the central bank to charge penalty rates.
} 
anything. ${ }^{15}$ From here it follows that the expected cost for the central bank if it supports the bank is $(1-u) v+(1-u) \beta c$, while the cost if it does not is simply $\beta c$.

Hence the central bank LLR policy is to support the bank if

$$
(1-u) v+(1-u) \beta c \leq \beta c
$$

that is if

$$
u \geq \widehat{u}(v) \equiv \frac{v}{v+\beta c} .
$$

The function $\widehat{u}(v)$ is clearly increasing, and satisfies $\widehat{u}(0)=0$ and $\widehat{u}(1)>u^{*} \cdot{ }^{16}$ Hence there is a unique $\widehat{v} \in(0,1)$ that solves the equation $\widehat{u}(v)=u^{*}$. Solving for $\widehat{v}$ and using (2) then gives

$$
\widehat{v} \equiv \frac{\beta c L}{R-L+c} .
$$

The central bank LLR policy is depicted in Figure 1. The shaded area to the left of $\widehat{v}$ corresponds to states in which the central bank is too soft, supporting the bank when it should be liquidated. In contrast, in the shaded area to the right of $\widehat{v}$ the central bank is excessively tough, not lending to the bank in states where it should be supported.

\section{[FIGURE 1]}

The intuition behind this result is easy to explain. When the liquidity shortfall $v$ is very small (and $u>0$ ) the central bank has a clear incentive to lend to the bank: if it does not the bank is liquidated at $t=1$ with probability 1 (and the central bank incurs a cost $\beta c$ ), whereas if it does the bank fails at $t=2$ with probability $1-u$ (and the central bank incurs an expected cost which is approximately equal to $(1-u) \beta c<\beta c)$. On the other hand, when $v$ is large the central bank has to take a large stake in the bank to keep it afloat, which it will be willing to do only if the probability of success $u$ is sufficiently large.

\footnotetext{
${ }^{15}$ This means that in the context of our simple model the seniority of central bank lending (an important ingredient of Bagehot's conception of the LLR) is irrelevant. It would be relevant, however, in a model in which $\widetilde{R}$ could take values in the interval $(0,1)$; see Section 5 below.

${ }^{16}$ To see this note that $\widehat{u}(1)>u^{*}$ if and only if $R-L+c(1-\beta L)>0$, which follows from $L<1<R$ and $\beta<1$.
} 
Deposit insurance corporation LLR policy Suppose now that the deposit insurance corporation is the LLR, and consider a situation in which after observing the signal $u$ the corporation has to decide whether to lend the bank the amount $v$ or let it fail.

As in the analysis of the central bank LLR policy, we initially assume that in the former case the deposit insurance corporation only charges the (risk unadjusted) market interest rate. Hence when $\widetilde{R}=R$ the bank will pay back the remaining depositors the amount $1-v$ and the deposit insurance corporation the amount $v$, whereas when $\widetilde{R}=0$ the deposit insurance corporation will get nothing from the bank and it will have to pay $1-v$ to the depositors of the failed bank. From here it follows that the expected cost for the deposit insurance corporation if it supports the bank is $(1-u)[v+(1-v)]+(1-u) \gamma c$.

On the other hand if the bank is allowed to fail the deposit insurance corporation will incur the cost $\gamma c$ with probability 1 , and in addition it will have to pay $1-L$ to the depositors, so the cost will be $(1-L)+\gamma c$.

Hence the deposit insurance corporation LLR policy is to support the bank if

$$
(1-u)+(1-u) \gamma c \leq(1-L)+\gamma c
$$

that is if

$$
u \geq \bar{u} \equiv \frac{L}{1+\gamma c} .
$$

The deposit insurance corporation LLR policy is depicted in Figure 2. Comparing (2) with (7) it is immediate to check that $\bar{u}>u^{*}$, so the shaded area above $u^{*}$ corresponds to states in which the corporation is too tough, not lending to the bank when it would be optimal from a first-best perspective to do so.

\section{[FIGURE 2]}

The intuition behind this result is the following. For $u=u^{*}$ the expected return of the bank's asset net of expected future bankruptcy costs is equal to the liquidation value of the bank's asset net of bankruptcy costs, so from a social point of view we are indifferent between continuation and liquidation. Since depositors are fully insured, and the bank owners get a positive expected return under continuation and zero upon 
liquidation, it must be the case that the deposit insurance corporation strictly prefers liquidation to continuation, so $\bar{u}>u^{*} \cdot{ }^{17}$

It is interesting to observe that the LLR policy of the deposit insurance corporation does not depend on the liquidity shortfall $v$. The reason for this is the following. Since depositors are fully insured, they always get 1 in present value terms (regardless of when they choose to withdraw), so the loss of the deposit insurance corporation is $\max \{1-\widetilde{R}, 0\}$, if the bank is supported, and $1-L$, otherwise.

To conclude this section we comment briefly on the differences between expressions (3) and (6) that characterize the LLR policies of the central bank and the deposit insurance corporation. Leaving aside the difference in the terms that correspond to the shares $\beta$ and $\gamma$ of the bankruptcy costs, two things should be noted. In the LHS of these expressions, if the bank is supported the central bank loses $v$ with probability $1-u$ while the deposit insurance corporation loses 1 with the same probability. In the RHS, if the bank is allowed to fail the central bank does not incur any direct losses while the deposit insurance corporation loses $1-L$. Hence as $v$ increases the central bank becomes less and less willing to support the bank, and eventually it becomes tougher than the deposit insurance corporation. Specifically, solving the equation $\widehat{u}(v)=\bar{u}$ gives a critical value

$$
\bar{v} \equiv \frac{\beta c L}{1-L+\gamma c}
$$

such that to the left (right) of $\bar{v}$ the central bank is softer (tougher) than the deposit insurance corporation. Since $\widehat{u}(v)$ is increasing and $u^{*}<\bar{u}$ it is clear that $\widehat{v}<\bar{v}$. Moreover, it is immediate to show that $c<1-L$ implies that $\bar{v}<1$. Hence we have the situation depicted in Figure 2.

It should finally be noted that in expressions (3) and (6) we are implicitly assuming that the rate for discounting future payoffs is the market interest rate. A higher discount rate for either of the two agencies could be introduced by multiplying the LHS of these expressions by a discount factor $\delta<1$. It is immediate to show that such discounting would shift $\widehat{u}(v)$ and $\bar{u}$ downwards, making both agencies softer as LLR. This result may be useful for understanding episodes of forbearance (like in the S\&L crisis). However, for the remainder of the paper we will assume $\delta=1$.

\footnotetext{
${ }^{17}$ Formally, $\left(1-u^{*}\right)+\left(1-u^{*}\right) \gamma c-(1-L)-\gamma c=L-u^{*}(1+\gamma c)>0$ because by the definition of $u^{*}$ we have $0=u^{*} R-\left(1-u^{*}\right) c-(L-c)=u^{*}(R-1)-\left(L-u^{*}(1+c)\right)$, and $u^{*}(R-1)>0$.
} 


\section{Optimal Allocation of LLR Responsibilities}

This section builds on the previous results in order to discuss the second-best optimal division of LLR responsibilities between the central bank and the deposit insurance corporation. Since the liquidity shock $v$ is verifiable, we can make the identity of the LLR contingent on the size of the shock. So we have to compute, for each $v$, the welfare cost of choosing the central bank or the deposit insurance corporation as LLR, and then select the agency that minimizes this cost. ${ }^{18}$

If the central bank is the LLR, this welfare cost is given by the function

$$
\widehat{L}(v) \equiv \int_{u^{*}}^{\widehat{u}(v)}[u(R+c)-L] d F(u)
$$

To explain this expression, observe that for $v<\widehat{v}$ there is an interval $\left[\widehat{u}(v), u^{*}\right)$ of values of $u$ over which the central bank is too soft, supporting the bank despite the fact that its expected social value under continuation, $u R-(1-u) c$, is smaller than its social value under liquidation, $L-c$. Hence we have $u R-(1-u) c-(L-c)=$ $u(R+c)-L<0$. This loss is then integrated between $u^{*}$ and $\widehat{u}(v)$ (to get a positive sign) using the probability distribution of $\widetilde{u}$. For $v>\widehat{v}$ there is an interval $\left[u^{*}, \widehat{u}(v)\right)$ of values of $u$ over which the central bank is too tough, not supporting the bank despite the fact that its expected social value under continuation is greater than its social value under liquidation, so $u(R+c)-L>0$. This loss is then integrated between $u^{*}$ and $\widehat{u}(v)$ using the probability distribution of $\widetilde{u}$.

Since the function $\widehat{u}(v)$ is increasing and intersects $u^{*}$ for $v=\widehat{v}$, it follows that the central bank loss function $\widehat{L}(v)$ is decreasing for $v<\widehat{v}$, increasing for $v>\widehat{v}$, and satisfies $\widehat{L}(\widehat{v})=0$.

Similarly, the welfare cost of choosing the deposit insurance corporation as LLR is given by

$$
\bar{L} \equiv \int_{u^{*}}^{\bar{u}}[u(R+c)-L] d F(u)
$$

To explain this expression, observe that for any liquidity shortfall $v$ there is an interval $\left[\bar{u}, u^{*}\right)$ of values of $u$ over which the deposit insurance corporation will not support

\footnotetext{
${ }^{18}$ This analysis assumes that both agencies observe the same signal $u$. If bank supervision is costly (and supervisory information can be transferred without cost) the efficient arrangement would be that only one of the agencies carries out the supervision and shares the information with the other. We will comment this issue at the end of the section.
} 
the bank despite the fact that $u(R+c)-L>0$. As before, this loss is integrated using the probability distribution of $\widetilde{u}$.

The optimal allocation of LLR responsibilities then follows from the comparison of $\widehat{L}(v)$ and $\bar{L}$. Given the relationship between $\widehat{u}(v), u^{*}$, and $\bar{u}$ depicted in Figure 2 , it is clear that $\widehat{L}(v)<\bar{L}$ for $v \in[\widehat{v}, \bar{v})$, and $\widehat{L}(v)>\bar{L}$ for $v \in(\bar{v}, 1]$. Hence allocating the LLR function to the central bank will be optimal for intermediate deposit withdrawals, while the deposit insurance corporation should be responsible for dealing with large withdrawals. However, for $v \in[0, \widehat{v})$ the relationship between $\widehat{L}(v)$ and $\bar{L}$ is in principle ambiguous.

In what follows we show that if

$$
E(\widetilde{u} \mid u \leq \bar{u}) \geq u^{*}
$$

then allocating the LLR function to the central bank will also be optimal for small deposit withdrawals. For this, we first note that since the function $\widehat{L}(v)$ is decreasing for $v \in[0, \widehat{v})$, it suffices to guarantee that

$$
\begin{aligned}
\bar{L}-\widehat{L}(0) & =\int_{0}^{\bar{u}}[u(R+c)-L] d F(u)=(R+c) \int_{0}^{\bar{u}} u d F(u)-L \int_{0}^{\bar{u}} d F(u) \\
& =[(R+c) E(\widetilde{u} \mid u \leq \bar{u})-L] F(\bar{u}) \geq 0 .
\end{aligned}
$$

But since by $(2)$ we have $(R+c) u^{*}-L=0$, the result follows.

Condition (11) holds if $F\left(u^{*}\right)$, the ex ante probability that it would be optimal to liquidate the bank at $t=1$, is sufficiently small relative to $F(\bar{u})$. To see this, observe that

$$
\begin{aligned}
E(\widetilde{u} \mid u \leq \bar{u}) & =\frac{1}{F(\bar{u})}\left[\int_{0}^{u^{*}} u d F(u)+\int_{u^{*}}^{\bar{u}} u d F(u)\right] \\
& =\frac{1}{F(\bar{u})}\left[F\left(u^{*}\right) E\left(\widetilde{u} \mid u \leq u^{*}\right)+\left(F(\bar{u})-F\left(u^{*}\right)\right) E\left(\widetilde{u} \mid u^{*}<u \leq \bar{u}\right)\right] \\
& =E\left(\widetilde{u} \mid u^{*}<u \leq \bar{u}\right)-\frac{F\left(u^{*}\right)}{F(\bar{u})}\left[E\left(\widetilde{u} \mid u^{*}<u \leq \bar{u}\right)-E\left(\widetilde{u} \mid u \leq u^{*}\right)\right] .
\end{aligned}
$$

Hence for $F\left(u^{*}\right) / F(\bar{u})$ sufficiently small the second term in the previous expression will be close to zero, so we have

$$
E(\widetilde{u} \mid u \leq \bar{u})-u^{*} \simeq E\left(\widetilde{u} \mid u^{*}<u \leq \bar{u}\right)-u^{*}>0
$$


The intuition for this result is easy to explain. For small deposit withdrawals the central bank is too soft, supporting the bank in states below $u^{*}$ when it would be optimal to liquidate it, while the deposit insurance corporation is too tough, not lending to the bank in states above $u^{*}$ when it would be optimal to support it. Now if states above $u^{*}$ are much more likely than states below $u^{*}$, it is clear that, in expected welfare terms, the softness of the central bank is going to be less costly for society than the toughness of the deposit insurance corporation. Hence, under this assumption, the central bank should be responsible for dealing with small and intermediate withdrawals $(v \leq \bar{v})$; on the other hand, for large withdrawals $(v>\bar{v})$ the decision should be in the hands of the deposit insurance corporation.

A simple parameterization will serve to illustrate our results. Suppose that $F(u)=$ $u^{n}$, for some $n>0$. Then it is immediate to show that

$$
E(\widetilde{u} \mid u \leq \bar{u})=\frac{n}{n+1} \bar{u}
$$

so using (2) and (7) we conclude that $E(u \mid u \leq \bar{u}) \geq u^{*}$ for

$$
n \geq \frac{u^{*}}{\bar{u}-u^{*}}=\frac{1+\gamma c}{R+c-(1+\gamma c)}
$$

For example, for $R=1.65, L=.45, c=.1$, and $\beta=\gamma=.5$ it suffices to pick $n \geq 1.5$; in particular, $n=2$ (the triangular distribution with density $F^{\prime}(u)=2 u$ ) will be sufficient. ${ }^{19}$ In this case $\bar{v}=.0375$, so for withdrawals smaller than $3.75 \%$ of the bank's balance sheet the central bank should be the LLR.

If condition (11) is not satisfied, there would exist $\overline{\bar{v}} \in(0, \bar{v})$ such that $\widehat{L}(\overline{\bar{v}})=$ $\bar{L}$, so the deposit insurance corporation should also be responsible for very small withdrawals $(v<\overline{\bar{v}}) \cdot{ }^{20}$ In this case, if the bank owners could somehow engineer higher withdrawals, they would increase them to $\overline{\bar{v}}$ in order to deal with a softer LLR. However, $\widehat{L}(\overline{\bar{v}})=\bar{L}$ implies that this strategy would not entail efficiency losses, since the welfare cost of the softness of the central bank would be equal to the welfare cost of the toughness of the deposit insurance corporation. At any rate, in what follows we will assume that (11) holds.

Under this condition, we can derive the effect of changes in the parameters of the model on the range $[0, \bar{v}]$ of liquidity shocks for which the central bank should be the

\footnotetext{
${ }^{19}$ Notice with this distribution $E(\widetilde{u})=2 / 3$, so $E(\widetilde{R})=R E(\widetilde{u})=1.1>1$.

${ }^{20}$ Since $\widehat{L}^{\prime}(0)=-L / \beta c$, for small $c$ we would expect $\overline{\bar{v}}$ to be close to zero.
} 
LLR. Using (8) it is immediate to check that $\bar{v}$ is increasing in $L$ (the liquidation value of the bank's asset), $c$ (the costs associated with bankruptcy), and $\beta$ (the share of these costs incurred or internalized by the central bank), and is decreasing in $\gamma$ (the share of these costs incurred by the deposit insurance corporation).

Now if we consider that the failure of a large bank is likely to have larger negative externalities that are of concern to the central bank, big banks would have large $c$ 's and large $\beta$ 's, ${ }^{21}$ so the range of shocks for which the central bank would be responsible would be larger. Moreover, both $\widehat{u}(v)$ and $\bar{u}$ would be shifted downwards, which leads to a "too big to fail" result: large banks would be supported more often than small banks.

To sum up, in this section we have characterized the optimal contingent allocation of LLR responsibilities. Under a fairly weak condition, we have shown that the central bank should be the LLR for shocks smaller than the critical value $\bar{v}$, and the deposit insurance corporation should take care of shocks greater than $\bar{v}$. Moreover, we expect big banks to have larger $\bar{v}$ 's, so for them the central bank should be responsible for a wider range of liquidity shocks.

These results can be used to shed some new light on the issue of which agency should be responsible for bank supervision. The traditional arguments for and against giving supervisory responsibilities to the central bank are summarized in Goodhart and Schoenmaker (1995). In short, the main argument against is that the combination of monetary policy with bank supervision might lead to conflicts of interest. The main argument for hinges on the role of the central bank in preserving the stability of the financial system. ${ }^{22}$ While these arguments are important, our approach to this issue is micro rather than macro. In our setup, bank supervision provides information for LLR decisions made by either the central bank or the deposit insurance corporation. If the costs of bank supervision are larger than the costs of transferring supervisory information, it is clear that only one agency should have supervisory responsibilities. Moreover, the allocation of these responsibilities should be made on the basis of which

\footnotetext{
${ }^{21}$ Recall that the volume of deposits is normalized to 1 , so bankruptcy $\operatorname{costs} c$ are relative to the size of the bank's balance sheet.

${ }^{22}$ An additional argument in favor of supervision by the central bank has been recently put forward by Peek, Rosengren and Tootell (1999). They show that confidential bank supervisory information helps to forecast macroeconomic variables, and also affects FOMC members' voting on monetary policy.
} 
of the two agencies needs to use the supervisory information more often. But then if we think that small liquidity shocks are more frequent than large shocks, our results suggest that it is the central bank that should be in charge of bank supervision. For small liquidity shocks the information would stay in house, while for large shocks it would be transferred for immediate use to the deposit insurance corporation.

\section{Extensions}

\subsection{Endogenous Liquidity}

Up until now we have assumed that the bank owners are completely passive. In what follows we discuss what happens when the model is extended to incorporate the possibility that they take some action at the initial date $t=0$ that affects the characteristics of the bank's asset returns.

Given that the model focuses on liquidity shocks, it is natural to consider an extension in which the bank is allowed to invest at $t=0$ a fraction of its deposits in a liquid asset that yields the market interest rate (which is normalized to zero). In particular, suppose that $x \in[0,1]$ is invested in the liquid asset, and $1-x$ is invested in the illiquid asset.

As before, at $t=1$ a fraction $v$ of the deposits are withdrawn. If $v \leq x$ the bank can use its holdings of the liquid asset to cover the deposit withdrawal. On the other hand, if $v>x$ the bank will be forced into liquidation unless it can borrow $x-v$ from the LLR. Bank supervision allows the LLR to observe both the investment $x$ in the liquid asset and the signal $u$ on the return $\widetilde{R}$ of the illiquid asset, but only the liquidity shortfall $\max \{x-v, 0\}$ is assumed to be verifiable.

It should be noticed that, in this setup, investment in the liquid asset is inefficient, since its return is lower than the expected return of the illiquid asset. However, in the absence of a LLR the bank will in general choose to invest in the liquid asset. To see this, observe that the expected return of the bank owners is

$$
E(\max \{(x+(1-x) \widetilde{R})-1,0\})=(1-x)(R-1) E(\widetilde{u})
$$


if $v \leq x$, and 0 otherwise. Therefore $x$ will be chosen to maximize

$$
(1-x)(R-1) E(\widetilde{u}) G(x),{ }^{23}
$$

which gives $x>0$ as long as $G^{\prime}(0)-G(0)>0$.

Next suppose that the deposit insurance corporation is the LLR. Assuming for simplicity that bankruptcy costs are proportional to the bank's investment in the illiquid asset, it follows that the expected cost for the deposit insurance corporation if it supports the bank when $v>x$ is

$$
(1-u)(1-x)+(1-u)(1-x) \gamma c=(1-x)[(1-u)+(1-u) \gamma c]
$$

while the cost if it does not is

$$
(1-x-(1-x) L)+(1-x) \gamma c=(1-x)[(1-L)+\gamma c]
$$

Hence the deposit insurance corporation LLR policy is to support the bank if (6) holds, which gives the same condition, $u \geq \bar{u}$, as before.

Given this policy, the bank owners will choose $x$ at $t=0$ to maximize

$$
(1-x)(R-1) E(\widetilde{u}) G(x)+(1-x)(R-1)\left(\int_{\bar{u}}^{1} u d F(u)\right)(1-G(x)) .
$$

The first term in this expression corresponds to what they get when $v \leq x$, and the second term to what they get when $v>x$. This term takes into account the fact that when $v>x$ the bank will only be supported by the deposit insurance corporation when $u \geq \bar{u}$. The previous objective function can be written in a more compact way as follows

$$
(1-x)(R-1)[a+b G(x)]
$$

where

$$
a \equiv \int_{\bar{u}}^{1} u d F(u) \quad \text { and } \quad b \equiv \int_{0}^{\bar{u}} u d F(u)
$$

A necessary condition for $x=0$ to be a solution is

$$
b\left[G^{\prime}(0)-G(0)\right]-a<0 .^{24}
$$

\footnotetext{
${ }^{23}$ Recall that $G(v)$ denotes the cumulative distribution function of the random variable $\widetilde{v}$.

${ }^{24}$ This condition would be sufficient if $(1-x) G^{\prime \prime}(x)-2 G^{\prime}(x)<0$, that is if $G(x)$ is not too convex.
} 
This condition will be satisfied if $\bar{u}$ is not too large, that is if the deposit insurance corporation is not excessively tough.

The intuition for this result can be explained as follows. Investing in the liquid asset has a benefit and a cost for the bank owners. The benefit is that they will be able reach date $t=2$ when $v \leq x$ and $u<\bar{u}$. The cost is that they will only be investing $1-x$ in the illiquid asset, which reduces their expected profits in states with $u \geq \bar{u}$. If $\bar{u}$ is not very large, the cost will be greater than the benefit, and so they will choose $x=0$, i.e. no investment in the liquid asset.

We have therefore shown that, under plausible conditions, the LLR policy of the deposit insurance corporation makes the bank owners reluctant to invest in the liquid asset. Since essentially the same result can be derived when the LLR is the central bank, we conclude that our previous results are robust to the introduction of a liquid asset in the model: in general, this asset is not going to be held in the banks' portfolios. Moreover, this happens to be efficient. In other words, the existence of a LLR not only allows the survival of banks which are illiquid but solvent, but also ensures that the banks will not want to waste resources in an asset which is dominated in terms of expected return.

\subsection{Bank Capital}

The bank in our model is assumed to have no capital. In what follows we start assuming that the bank funds a proportion $k$ of its investment in the illiquid asset at date $t=0$ with equity capital (and $1-k$ with deposits), and consider its effects on the LLR policies of the central bank and the deposit insurance corporation, as well as on the optimal allocation of LLR responsibilities. Then we look at the decision problem of the bank owners at the initial date $t=0$, and show that they prefer to hold no capital $(k=0)$, so the assumption that we have made so far is justified. Finally, we note that if a capital requirement is imposed by regulation, the effect would be to expand the range of liquidity shocks for which the central bank should be the LLR.

Consider first a situation in which the central bank has to decide whether to lend the bank the required amount $v$, given signal $u$ on the future return of the bank's portfolio. Since neither the expected cost for the central bank if it supports the bank, nor the cost if it does not, depend on $k$, it follows that the central bank LLR policy 
is the same as before, i.e. it will support the bank if $u \geq \widehat{u}(v)$, where $\widehat{u}(v)$ is given by (4).

Consider next the LLR policy of the deposit insurance corporation. Since the amount of deposits is now $1-k$, it follows that the expected cost for the deposit insurance corporation if supports the bank is $(1-u)(1-k)+(1-u) \gamma c$, while the cost if it does not is $(1-k-L)+\gamma c{ }^{25}$ Hence the deposit insurance corporation LLR policy is to support the bank if

$$
(1-u)(1-k)+(1-u) \gamma c \leq(1-k-L)+\gamma c
$$

that is if

$$
u \geq \bar{u}(k) \equiv \frac{L}{1-k+\gamma c}
$$

Since the function $\bar{u}(k)$ is increasing, if follows that bank capital makes the deposit insurance corporation tougher. The intuition for this is the following. The existence of bank capital reduces the expected cost of supporting the bank by $(1-u) k$, but the cost of not supporting it is reduced by $k$, so the deposit insurance corporation is now more inclined to be tough.

From here, and following the same arguments as in Section 3, it is immediate to conclude that the optimal division of LLR responsibilities is to allocate the LLR function to the central bank for $v \in\left(0, \bar{v}_{k}\right]$, and to the deposit insurance corporation for $v \in\left[\bar{v}_{k}, 1-k\right]$, where the critical value $\bar{v}_{k}$ is the solution to the equation $\widehat{u}(v)=$ $\bar{u}(k)$, which gives

$$
\bar{v}_{k} \equiv \frac{\beta c L}{1-k-L+\gamma c} .
$$

However, how much capital would the bank owners choose to hold at date $t=0$ ? Their decision is going to depend on the allocation of LLR responsibilities. To simplify the presentation, suppose that the central bank is the LLR. To compute the expected payoff of the bank owners when a proportion $k$ of the bank's portfolio is financed with equity, observe that if the bank is liquidated at date $t=1$, the owners get nothing. On the other hand, if the bank continues in operation until date $t=2$ (which under the LLR policy of the central bank happens when $u \geq \widehat{u}(v)$ ), they will get $R-(1-k)$, with probability $u$, and zero otherwise. Hence their expected payoff,

\footnotetext{
${ }^{25}$ Assuming $k \leq 1-L$. Otherwise the cost would be $\max \{1-k-L, 0\}+\gamma c$.
} 
net of the opportunity cost of their capital (evaluated at market interest rates), is given by

$$
\begin{aligned}
& (R-(1-k)) \int_{0}^{1} \int_{\widehat{u}(v)}^{1} u d F(u) d G(v)-k \\
= & (R-1) \int_{0}^{1} \int_{\widehat{u}(v)}^{1} u d F(u) d G(v)-k\left[1-\int_{0}^{1} \int_{\widehat{u}(v)}^{1} u d F(u) d G(v)\right] .
\end{aligned}
$$

Since the term in square brackets is positive, the expression is decreasing in $k$, so the maximum will be found for $k=0$.

The intuition for this result is quite simple. Since the bank owners can entirely fund its investment with insured deposits, it is clear that they prefer to use the depositors' funds rather than their own: they get all the profits in good states of nature, and bear none of the costs in bad states. It is also clear that the argument can be extended to the case in which the LLR is the deposit insurance corporation or is selected on the basis of the realization of the verifiable liquidity shock (the only difference is that the term in square brackets would be a function of $k$ ).

Since the bank owners would not want to hold any equity, we next assume that regulation requires the bank to hold capital in a proportion $k>0$ of its assets. In this case we have seen that the optimal division of LLR responsibilities between the central bank and the deposit insurance corporation is characterized by the critical value $\bar{v}_{k}$ given in (12). Since $\bar{v}_{k}$ is increasing in $k$, it follows that the introduction of a capital requirement expands the range of liquidity shocks for which the central bank should be the LLR.

For example, using the same parameter values as in Section $3(R=1.65, L=.45$, $c=.1$, and $\beta=\gamma=.5)$ we get that a capital requirement of $10 \%$ increases the critical value of the liquidity shock below which the central bank should be the LLR from $3.75 \%$ to $4.5 \%$ of the bank's balance sheet.

\subsection{Penalty Rates}

We next consider a variation of the model in which both the central bank and the deposit insurance corporation a allowed to charge penalty rates in their LLR operations. In particular, assume that following the observation of $u$ and $v$ the LLR has to decide whether to lend the bank the amount $v$ at an interest rate $r \in[0, \bar{r}]$, or let the 
bank fail. Since the liquidity shortfall $v$ is verifiable, the interest rate $r$ can be made contingent on $v$.

The ceiling $\bar{r}$ on the interest rate $r$ is introduced in order to limit the rents that the LLR can extract from the bank owners. In the absence of such constraint, we could easily approximate the first-best by letting the deposit insurance corporation charge an infinite interest rate, so it effectively becomes the banks' residual claimant. To simplify the analysis we also assume that $\bar{r} \leq R-1$.

The central bank LLR policy when it charges an interest rate $r$ is to support the bank if

$$
(1-u) v-u r v+(1-u) \beta c \leq \beta c .
$$

The difference between this expression and (3) lies in the term - urv, which takes into account the fact that with probability $u$ the central bank will recover the loan, and net the interest $r v \cdot{ }^{26}$ Hence the central bank will support the bank if

$$
u \geq \widehat{u}(r, v) \equiv \frac{v}{(1+r) v+\beta c} .
$$

Since $\widehat{u}(r, v)$ is decreasing in $r$, it follows that penalty rates induce the central bank to be softer. This is clearly not desirable for deposit withdrawals below $\widehat{v}$ (for which the central bank is already too soft). ${ }^{27}$ However for withdrawals greater than $\widehat{v}$ the interest rate $r$ can be made contingent on $v$ in a way that improves the decision of the central bank. In particular, the optimal interest rate is obtained by solving the equation $\widehat{u}(r, v)=u^{*}$, and taking into account the constraint $r \leq \bar{r}$, which gives

$$
r(v) \equiv\left\{\begin{array}{cl}
\frac{R-L+c}{L}-\frac{\beta c}{v}, & \text { if } \widehat{v} \leq v \leq \widehat{v}_{\bar{r}} \\
\bar{r}, & \text { if } \widehat{v}_{\bar{r}}<v \leq 1
\end{array},\right.
$$

where

$$
\widehat{v}_{\bar{r}} \equiv \frac{\beta c L}{R-(1+\bar{r}) L+c} .
$$

The function $r(v)$ is increasing and satisfies $r(\widehat{v})=0$ and $r\left(\widehat{v}_{\bar{r}}\right)=\bar{r}$. Moreover it is easy to check that $\widehat{v}_{\bar{r}}<1$, so for large deposit withdrawals the constraint $r \leq \bar{r}$ is binding.

\footnotetext{
${ }^{26}$ Notice that $r \leq \bar{r} \leq R-1$ and $v \leq 1$ imply $(1-v)+(1+r) v=1+r v \leq 1+\bar{r} v \leq R$, so the return $R$ is sufficient to pay back the remaining depositors and the central bank's loan.

${ }^{27}$ In fact, in this range lower than market interest rates would be appropriate. Although this would be consistent with the discount window policy of the US Federal Reserve System, we can rule it out if banks can, at low cost, engineer higher withdrawals.
} 
The central bank LLR policy with penalty rates is depicted in Figure 3. As before, the shaded area to the left of $\widehat{v}$ corresponds to states in which the central bank is too soft, while in the shaded area to the right of $\widehat{v}_{\bar{r}}$ the central bank is excessively tough.

\section{[FIGURE 3]}

The deposit insurance corporation LLR policy when it charges an interest rate $r$ is to support the bank if

$$
(1-u)-u r v+(1-u) \gamma c \leq(1-L)+\gamma c
$$

The difference between this expression and (6) lies in the term -urv, which takes into account the fact that with probability $u$ the deposit insurance corporation will recover the loan, and net the interest $r v$. Hence the corporation will support the bank if

$$
u \geq \bar{u}(r, v) \equiv \frac{L}{1+r v+\gamma c} .
$$

Since $\bar{u}(r, v)$ is decreasing in $r$, it follows that penalty rates induce the deposit insurance corporation to be softer. Moreover, since one can check that $\bar{u}(r, v)>u^{*}$ for all $r \in[0, \bar{r}]$ and $v \in[0,1]$, the deposit insurance corporation should charge the maximum interest rate $\bar{r}$.

The deposit insurance corporation LLR policy with penalty rates is depicted in Figure 4 . The shaded area above $u^{*}$ corresponds to states in which the corporation is too tough, not lending to the bank when it would be optimal to do so.

\section{[FIGURE 4]}

To derive the optimal allocation of LLR responsibilities in the model with penalty rates, we have to analyze the relationship between the functions $\widehat{u}(\bar{r}, v)$ and $\bar{u}(\bar{r}, v)$. Given the fact that the former is increasing and the latter is decreasing in $v$, that $\widehat{u}\left(\bar{r}, \widehat{v}_{R}\right)=u^{*}<\bar{u}\left(\bar{r}, \widehat{v}_{R}\right)$, and that $\widehat{u}(\bar{r}, L)>\bar{u}(\bar{r}, L),{ }^{28}$ there exists a critical value $\bar{v}_{\bar{r}} \in\left(\widehat{v}_{\bar{r}}, L\right)$ such that $\widehat{u}\left(\bar{r}, \bar{v}_{\bar{r}}\right)=\bar{u}\left(\bar{r}, \bar{v}_{\bar{r}}\right)$; see Figure 4 . Now using the same arguments

\footnotetext{
${ }^{28}$ To check this observe that $\widehat{u}(\bar{r}, L)>\bar{u}(\bar{r}, L)$ if and only if $1-L>(\beta-\gamma) c$, which follows from the assumption $c<1-L$.
} 
as in Section 3, we conclude that the central bank should be the LLR for shocks smaller than $\bar{v}_{\bar{r}}$, and the deposit insurance corporation should be responsible for dealing with shocks greater than $\bar{v}_{\bar{r}}$.

Moreover, one can show that if $\bar{r}$ is not too large the critical value $\bar{v}_{\bar{r}}$ for the model with penalty rates will be greater than the critical value $\bar{v}$ for the model without them. ${ }^{29}$ For example, for the parameter values used in Section 3 we get that an interest rate ceiling of $25 \%$ increases the critical value of the liquidity shock below which the central bank should be the LLR from $3.75 \%$ to $4.51 \%$ of the bank's balance sheet.

To sum up, the introduction of penalty rates does not change our qualitative results on the optimal allocation of LLR responsibilities. In addition, the central bank should not charge penalty rates for very small loans, gradually increasing the rate as the size of the loan exceeds some critical value. Finally, the deposit insurance corporation should always charge the maximum rate allowed.

It is interesting to note that our rationale for penalty rates is very different from the one in Bagehot (1873, p. 97): "That no one may borrow out of idle precaution without paying well for it." Instead of addressing the incentives of the banks, we focus on the incentives of the LLR. In our model, penalty rates for withdrawals above $\widehat{v}$ make both the central bank and the deposit insurance corporation softer, bringing their policies closer to the first-best.

\section{A More General Setup}

The model studied so far incorporates a number of simplifying assumptions. In particular, we have assumed that the probability distribution of the return $\widetilde{R}$ of the illiquid asset has a two-point support. This is a very implausible assumption, if we think of the illiquid asset as a portfolio of bank loans. Also, we have assumed that the liquidation value of this asset at date $t=1$ is a constant $L$, which is obviously uncorrelated with the return $\widetilde{R}$ at date $t=2$. Surely if the future does not look very promising, one should not expect to get very much upon liquidation. In this section,

\footnotetext{
${ }^{29}$ Solving $\widehat{u}(\bar{r}, v)=\bar{u}(\bar{r}, v)$ gives the quadratic equation $\bar{r} v^{2}+(1-(1+\bar{r}) L+\gamma c)-\beta c L=0$. Differentiating this equation, and using the fact that $\bar{v}_{\bar{r}}<L$, then gives $d \bar{v}_{\bar{r}} / d \bar{r}>0$ if $1-(1+\bar{r}) L+$ $\gamma c>0$.
} 
we discuss a generalization of the model that relaxes these two assumptions.

Suppose that the distribution of the return $\widetilde{R}$ conditional on the supervisory information $u$ is described by a continuous cumulative distribution function

$$
D(R \mid u) \equiv(1-u) D_{0}(R)+u D_{1}(R)
$$

where $D_{0}(R) \geq D_{1}(R)$. Similarly, suppose that the liquidation value of the asset is a random variable $\widetilde{L}$ with continuous cumulative distribution function

$$
H(L \mid u) \equiv(1-u) H_{0}(L)+u H_{1}(L),
$$

where $H_{0}(L) \geq H_{1}(L)$. This means that high $u$ 's are a good signal for asset returns and liquidation values in the sense of first-order stochastic dominance. From here it follows that

$$
E(\widetilde{R} \mid u)=(1-u) R_{0}+u R_{1} \text {, and } E(\widetilde{L} \mid u)=(1-u) L_{0}+u L_{1},
$$

where

$$
R_{0} \equiv \int R d H_{0}(R) \leq \int R d H_{1}(R) \equiv R_{1} \text {, and } L_{0} \equiv \int L d D_{0}(L) \leq \int L d D_{1}(L) \equiv L_{1} .
$$

In addition, suppose that

$$
R_{0}<L_{0}<L_{1}<1-c<1<R_{1} \text {. }
$$

This implies that $E(\widetilde{R} \mid u)$ and $E(\widetilde{L} \mid u)$ are both increasing in $u$, and the difference $E(\widetilde{R} \mid u)-E(\widetilde{L} \mid u)$ is also increasing in $u$, so the effect of $u$ on expected future returns is greater than its effect on expected liquidation values. Finally, to simplify the presentation we assume that $D_{0}(1)=1, D_{1}(1)=0$, and $H_{0}(1)=H_{1}(1)=1$. This implies that the conditional probability that the bank will fail at $t=2$ is simply $D(1 \mid u)=1-u$, and that liquidating the bank at $t=1$ always produces loses for the deposit insurance corporation.

In this setup the optimal LLR policy is to support the bank if the expected return of the bank's asset net of expected future bankruptcy costs is greater than the expected liquidation value of the bank's asset net of bankruptcy costs, that is if

$$
E(\widetilde{R} \mid u)-(1-u) c \geq E(\widetilde{L} \mid u)-c
$$


which reduces to

$$
u \geq u^{*} \equiv \frac{L_{0}-R_{0}}{\left(R_{1}-L_{1}\right)+\left(L_{0}-R_{0}\right)+c} .
$$

On the other hand, the LLR policy of the central bank is to support the bank if the expected costs for the central bank of doing so are smaller than $\beta c$, that is if

$$
v-E(\min \{\widetilde{R}, v\} \mid u)+(1-u) \beta c \leq \beta c .
$$

In this expression we are implicitly assuming that the central bank loan is collateralized, so its debt is senior to any other claim (in particular that of depositors). ${ }^{30}$ Integrating by parts one can show that

$$
v-E(\min \{\widetilde{R}, v\} \mid u)=\int_{0}^{v} D(R \mid u) d R,
$$

so using (15) and the assumption $D_{1}(1)=0$ we conclude that the central bank will support the bank if

$$
u \geq \widehat{u}(v) \equiv \frac{\int_{0}^{v} D_{0}(R) d R}{\int_{0}^{v} D_{0}(R) d R+\beta c} .
$$

As before, the function $\widehat{u}(v)$ is increasing, and satisfies $\widehat{u}(0)=0$ and $\widehat{u}(1)>u^{*},{ }^{31}$ so there is a unique $\widehat{v} \in(0,1)$ that solves the equation $\widehat{u}(v)=u^{*}$. Hence we get the same characterization of the central bank LLR policy.

Finally, the LLR policy of the deposit insurance corporation if its expected costs under continuation are smaller than the expected costs under liquidation, that is if

$$
1-E(\min \{\widetilde{R}, 1\} \mid u)+(1-u) \gamma c \leq 1-E(\widetilde{L} \mid u)-\gamma c .
$$

Now using (15) and (16), together with the assumptions $D_{0}(1)=1, D_{1}(1)=0$, and $H_{0}(1)=H_{1}(1)=1$, one can show that this condition reduces to

$$
u \geq \bar{u} \equiv \frac{L_{0}-R_{0}}{\left(1-L_{1}\right)+\left(L_{0}-R_{0}\right)+\gamma c} .
$$

Comparing (19) with (17) we get $\bar{u}>u^{*}$, so as before the deposit insurance corporation is too tough, not lending to the bank in states where it should be supported.

Also, we can easily prove that the function $\widehat{u}(v)$ defined in (18) equals $\bar{u}$ for some $\bar{v} \in(\widehat{v}, 1)$, for which however there is no explicit solution. From here we can proceed

\footnotetext{
${ }^{30}$ At the end of this section we will discuss the desirability of giving seniority to the debt of the central bank.

${ }^{31}$ To see this note that $D_{0}(1)=1$ implies $\int_{0}^{1} D_{0}(R) d R=1-R_{0}$.
} 
to derive the optimal allocation of LLR responsibilities. It should be obvious by now that, under suitable assumptions, all of our previous results can be extended to this more general setup, so we need not go any further.

To conclude this section we briefly comment on whether central bank debt should be fully collateralized, and hence be senior to all other claims. Seniority reduces the expected costs for the central bank of supporting the bank, and hence makes it softer as LLR. As in the case of penalty rates, this is clearly not desirable for deposit withdrawals below $\widehat{v}$. Therefore our model suggests that for very small liquidity shocks it would be a good idea to collateralize only a fraction of the central bank loan. The practical problem is to how gather ex ante the statistical information on asset returns that would be needed to tailor the optimal coverage to the size of the shock. In the absence of such information, partial collateralization may make matters worse by pushing the function that characterizes the central bank's LLR policy above $u^{*}$.

\section{Concluding Remarks}

This paper has investigated under what conditions the central bank should act as lender of last resort (LLR) in an environment where bank deposits are insured by a deposit insurance corporation. LLR operations are justified by (i) the existence of an asymmetric information problem with regard to the value of the bank's assets (in fact, the same problem that makes bank loans illiquid), and (ii) the possibility of acquiring private information via bank supervision. It follows from (ii) that there is a connection between acting as LLR and having immediate access to supervisory information. For this reason, the paper also sheds some light on the issue of whether the central bank should be in charge of bank supervision.

The approach taken in the paper is micro, and borrows heavily from the recent literature on incomplete contracts. In our setup, the outcome of bank supervision is nonverifiable, so LLR decisions crucially depend on the preferences of the lending agency. Both the central bank and the deposit insurance corporation can act as LLR, and we assume that they have different preferences which do not coincide with the maximization of social welfare. The final twist is that the liquidity shock is verifiable, so the allocation of LLR responsibilities can be made contingent on the size of the 
shock.

The main result of the paper is that, under a fairly weak condition, the central bank should be responsible for dealing with small liquidity shocks (relative to the size of the bank), and the deposit insurance corporation should take care of large shocks. If small shocks are more frequent than large ones, this result suggests that, in order to avoid duplication of supervisory costs, the central bank should be responsible for bank supervision.

It is interesting to note that the related literature on banking regulation has put a lot of emphasis on moral hazard issues (in particular risk-shifting incentives) which play no role in our model. Clearly the expectation of LLR support may induce bank owners to take on more risk. However, if this support is conditional on good supervisory information, and charter values are sufficiently large, the possibility of not getting the support and then lose the bank's charter may lead them to choose low risk strategies. ${ }^{32}$ Hence in these cases risk-shifting incentives may not be very relevant.

A more important criticism is that the liquidity shocks in the paper come from withdrawals of insured deposits, while in reality the shocks that call for LLR support are likely to be associated with sudden outflows of uninsured interbank liabilities. However, modelling this would require a much more complicated setup with both interbank lending and some coordination problem among imperfectly informed lenders. Two recent papers by Morris and Shin (1999a,b) offer some hope for progress on this front. In particular, the second paper considers a coordination problem among a large number of imperfectly informed creditors that can foreclose on a loan fearing that similar action by other creditors may undermine the value of the firm. For a particular parameterization of uncertainty, they show that there is a unique equilibrium characterized by a switching strategy: the creditors foreclose on the loan if and only if their best estimate of the firm's fundamental value is below some benchmark. Moreover, this benchmark is strictly above the firm's solvency threshold, so we have inefficient liquidations. Using this framework for addressing some of the issues considered in this paper seems a very promising avenue for future research.

\footnotetext{
${ }^{32}$ This argument is developed by Keeley (1990) for a static setting (with exogenous charter values), and extended by Suarez (1994) to a dynamic setting (with endogenous charter values).
} 


\section{References}

[1] Aghion, Philippe, and Patrick Bolton. "An Incomplete Contracts Approach to Financial Contracting." Review of Economic Studies 59 (1992), 473-494.

[2] Bagehot, Walter. Lombard Street. A Description of the Money Market. New York: Scribner, Armstrong \& Co., 1873. References from the 1962 edition, Homewood, Ill: Richard D. Irwin, Inc.

[3] Bhattacharya, Sudipto, and Douglas Gale. "Preference Shocks, Liquidity, and Central Bank Policy." In New Approaches to Monetary Economics, edited by W. Barnett and K. Singleton, pp. 69-88. Cambridge: Cambridge University Press, 1987.

[4] Calomiris, Charles W., and Charles M. Kahn. "The Role of Demandable Debt in Structuring Optimal Banking Arrangements." American Economic Review 81 (1991), 497-513.

[5] Dewatripont, Mathias, and Jean Tirole. The Prudential Regulation of Banks. Cambridge, Mass.: MIT Press, 1993.

[6] Dewatripont, Mathias, and Jean Tirole. "A Theory of Debt and Equity: Diversity of Securities and Manager-Shareholder Congruence." Quarterly Journal of Economics 109 (1994), 1027-1054.

[7] Diamond, Douglas. "Financial Intermediation and Delegated Monitoring." Review of Economic Studies 51 (1984), 393-414.

[8] Freixas, Xavier. "Optimal Bail Out Policy, Conditionality and Creative Ambiguity." Mimeo, 1999.

[9] Freixas, Xavier, Bruno Parigi and Jean-Charles Rochet. "Systemic Risk, Interbank Relations and Liquidity Provision by the Central bank." Mimeo, 1999.

[10] Flannery, Mark. "Financial Crises, Payment System Problems, and Discount Window Lending." Journal of Money, Credit and Banking 28 (1996), 804-824. 
[11] Goodfriend, Marvin, and Jeffrey Lacker. "Limited Commitment and Central Bank Lending." Mimeo, 1999.

[12] Goodhart, Charles, and Haizhou Huang. "A Model of the Lender of Last Resort." IMF Working Paper 99/39, 1999.

[13] Goodhart, Charles, and Dirk Schoenmaker. "Should the Functions of Monetary Policy and Banking Supervision Be Separated?" Oxford Economic Papers 47 (1995), 539-560.

[14] Keeley, Michael C. "Deposit Insurance, Risk, and Market Power in Banking." American Economic Review 80 (1990), 1183-1200.

[15] Mailath, George J., and Loretta J. Mester. "A Positive Analysis of Bank Closure." Journal of Financial Intermediation 3 (1994), 272-299.

[16] Morgan, Donald P. "Judging the Risk of Banks: What Makes Banks Opaque?", Mimeo, 1998.

[17] Morris, Stephen, and Hyun Song Shin. "Private versus Public Information in Coordination Problems." Mimeo, 1999a.

[18] Morris, Stephen, and Hyun Song Shin. "Coordination Risk and the Price of Debt." Mimeo, 1999b.

[19] Peek, Joe, Eric Rosengren, and Geoffrey Tootell. "Is Bank Supervision Central to Central Banking?" Quarterly Journal of Economics 114 (1999), 629-653.

[20] Rochet, Jean-Charles, and Jean Tirole. "Interbank Lending and Systemic Risk." Journal of Money, Credit and Banking 28 (1996), 733-762.

[21] Suarez, Javier. "Closure Rules, Market Power and Risk-Taking in a Dynamic Model of Bank Behaviour." LSE Financial Markets Group Discussion Paper No. 196, 1994. 


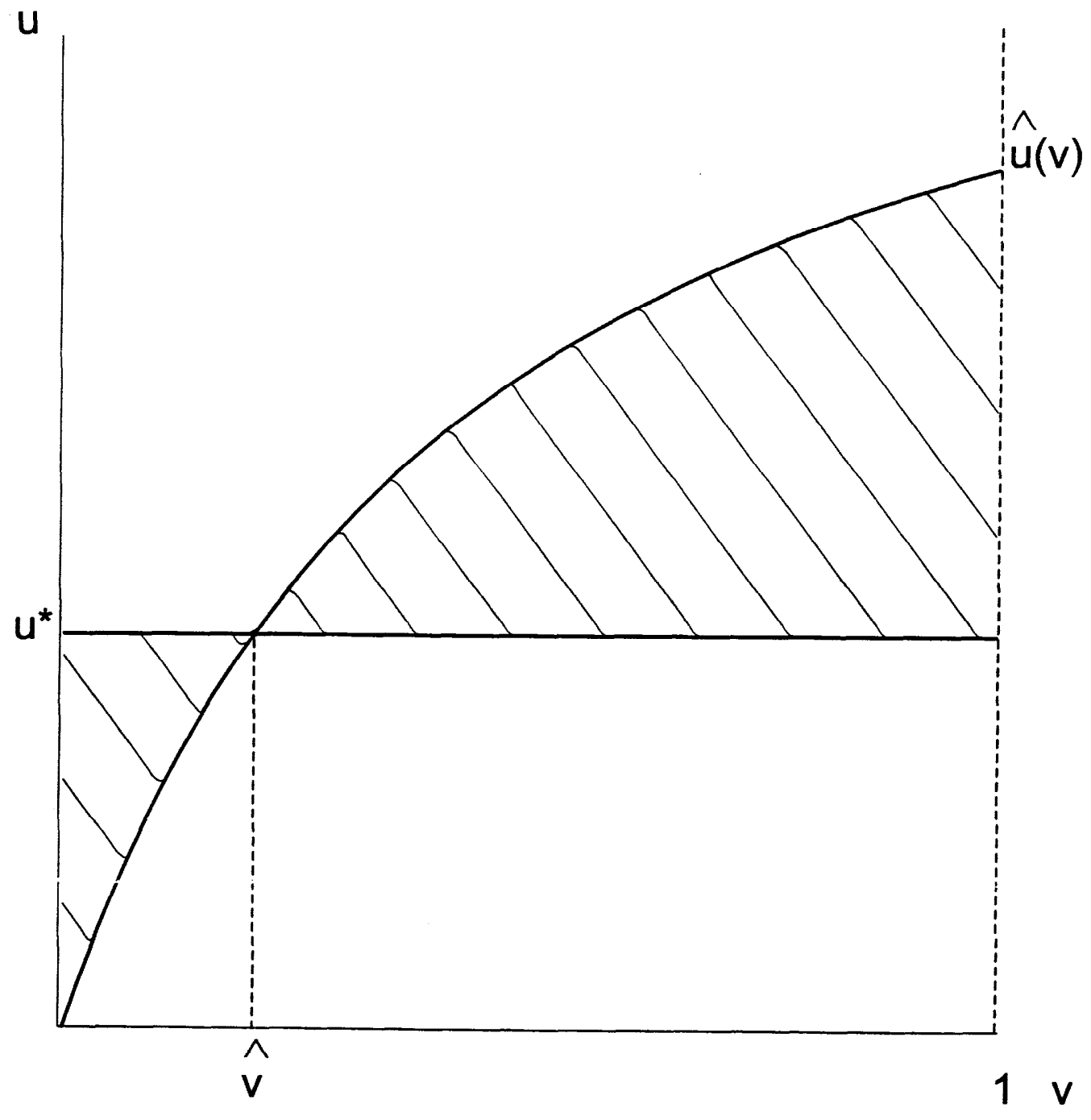

FIGURE 1: Central Bank LLR Policy 


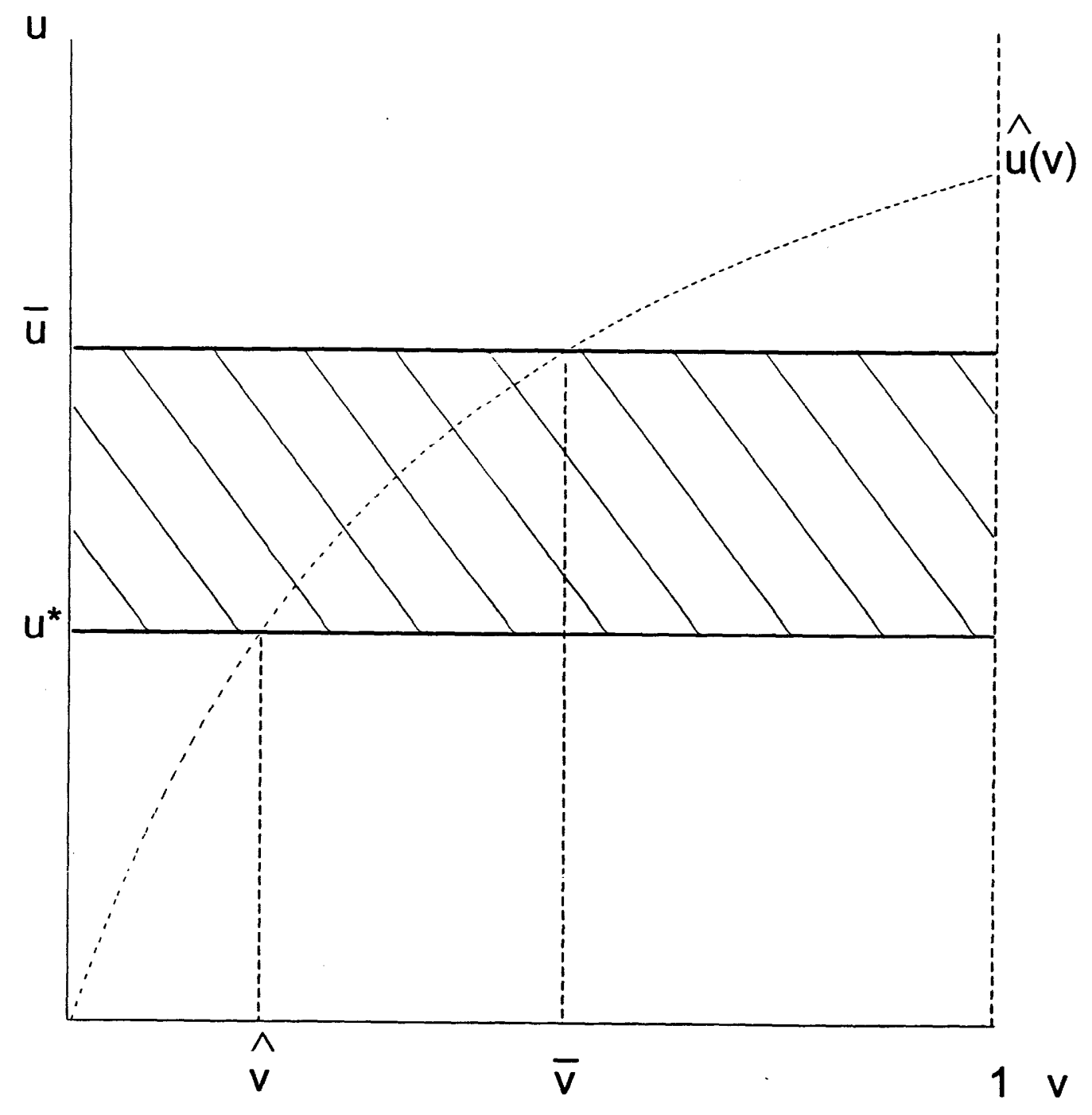

FIGURE 2: Deposit Insurance Corporation LLR Policy 


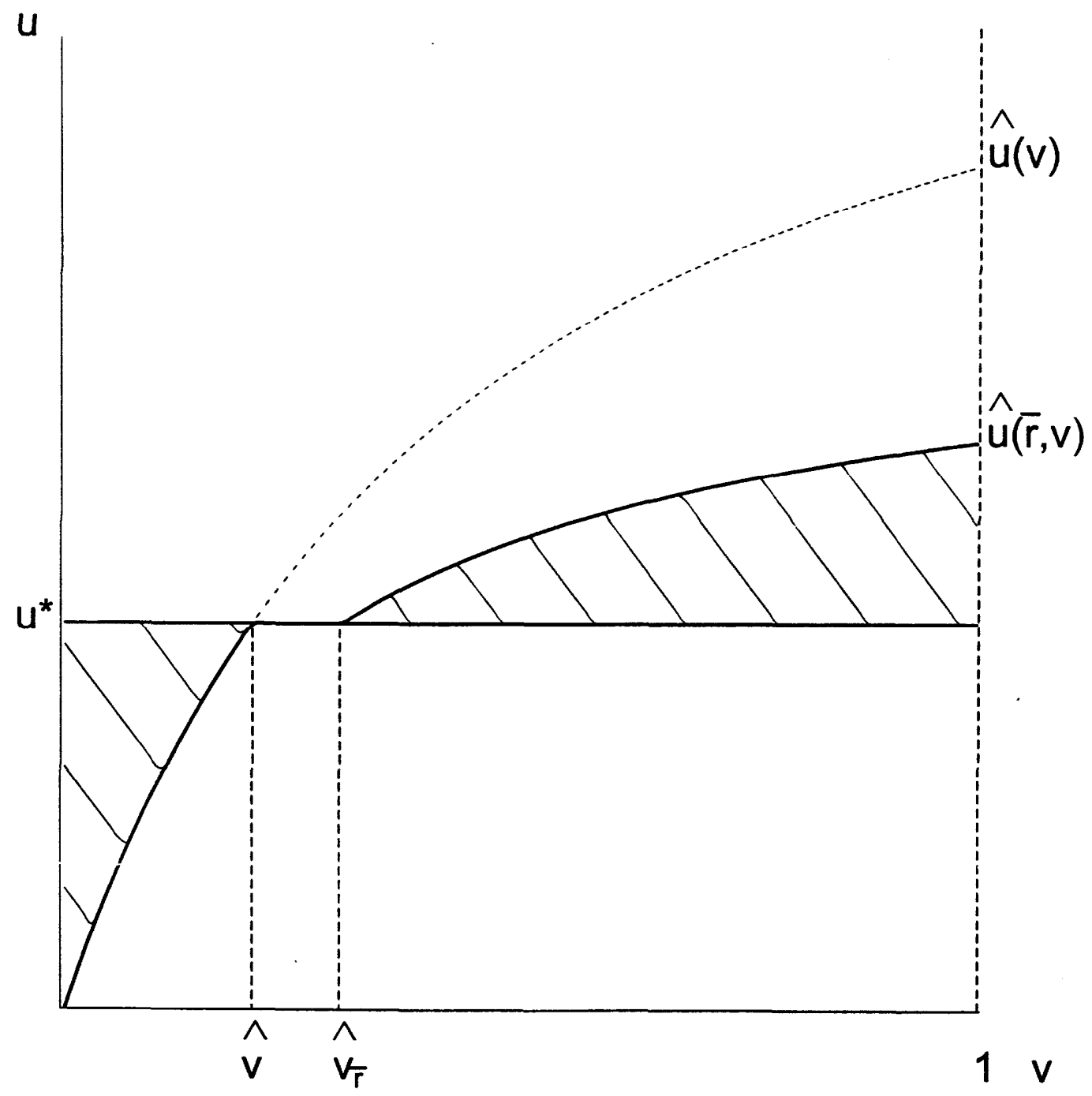

FIGURE 3: Central Bank LLR Policy with Penalty Rates 


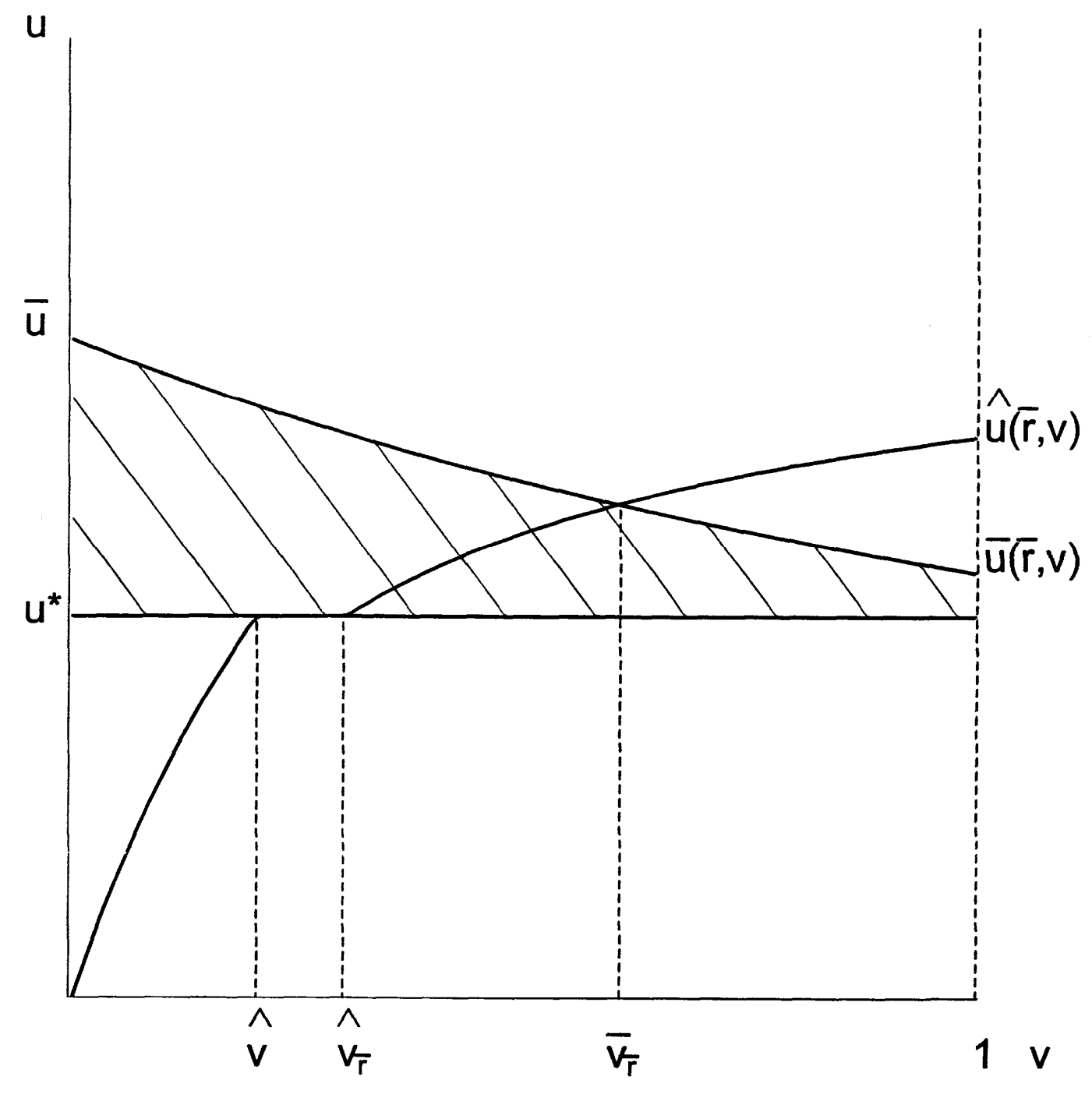

FIGURE 4: Deposit Insurance Corporation LLR Policy with Penalty Rates 